University of Nebraska - Lincoln

DigitalCommons@University of Nebraska - Lincoln

\title{
Role of Copper Oxide Layer on Pool Boiling Performance with Femtosecond Laser Processed Surfaces
}

Corey Kruse

Edwin Peng

Craig Zuhlke

Jeff Shield

Dennis Alexander

See next page for additional authors

Follow this and additional works at: https://digitalcommons.unl.edu/mechengfacpub

Part of the Mechanics of Materials Commons, Nanoscience and Nanotechnology Commons, Other Engineering Science and Materials Commons, and the Other Mechanical Engineering Commons

This Article is brought to you for free and open access by the Mechanical \& Materials Engineering, Department of at DigitalCommons@University of Nebraska - Lincoln. It has been accepted for inclusion in Mechanical \& Materials Engineering Faculty Publications by an authorized administrator of DigitalCommons@University of Nebraska Lincoln. 


\section{Authors}

Corey Kruse, Edwin Peng, Craig Zuhlke, Jeff Shield, Dennis Alexander, Sidy Ndao, and George Gogos 


\title{
Role of Copper Oxide Layer on Pool Boiling Performance with Femtosecond Laser Processed Surfaces
}

\author{
Corey Kruse \\ Mechanical and Materials Engineering, \\ University of Nebraska - Lincoln, Lincoln, NE, USA \\ Edwin Peng \\ Mechanical and Materials Engineering, \\ University of Nebraska - Lincoln, Lincoln, NE, USA \\ Craig Zuhlke \\ Electrical and Computer Engineering, \\ University of Nebraska - Lincoln, Lincoln, NE, USA

\section{Jeff Shield} \\ Mechanical and Materials Engineering, \\ University of Nebraska - Lincoln, Lincoln, NE, USA

\section{Dennis Alexander} \\ Electrical and Computer Engineering, \\ University of Nebraska - Lincoln, Lincoln, NE, USA

\section{Sidy Ndao} \\ Mechanical and Materials Engineering, \\ University of Nebraska - Lincoln, Lincoln, NE, USA

\section{George Gogos} \\ Mechanical and Materials Engineering, \\ University of Nebraska - Lincoln, Lincoln, NE, USA
}

\footnotetext{
Published in: Proceedings of the ASME 2017 15th International Conference on Nanochannels, Microchannels, and Minichannels, August 27-30, 2017, Cambridge, Massachusetts, USA ICNMM2017, Paper No. 5574.

Copyright (c) 2017 ASME. Used by permission.
} 


\begin{abstract}
Copper pool boiling surfaces are tested for pool boiling enhancement due to femtosecond laser surface processing (FLSP). FLSP creates self-organized micro/nanostructures on metallic surfaces and creates highly wetting and wicking surfaces with permanent surface features. In this study two series of samples were created. The first series consists of three flat FLSP copper surfaces with varying microstructures and the second series is an open microchannel configuration with laser processing over the horizontal surfaces of the microchannels. These microchannels range in height from 125 microns to 380 microns. Each of these surfaces were tested for pool boiling performance. It was found that all the processed surfaces except one resulted in a decrease in critical heat flux and heat transfer coefficient compared to an unprocessed surface. It was found that the laser fluence parameter had a significant role in whether there was an increase in CHF or HTC. A cross sectioning technique was employed to study the different layers of the microstructure and to understand how FLSP could have a negative effect on the CHF and HTC. It was found that a thick oxide layer forms during the FLSP process of copper in an open-air atmosphere. The thickness and uniformity of the oxide layer is highly dependent on the laser fluence. A low fluence sample results in an inconsistent oxide layer of nonuniform thickness and subsequently an increase in CHF and HTC. A high laser fluence sample results in a uniformly thick oxide layer which increases the thermal resistance of the sample and allows for a premature CHF and decrease in HTC.
\end{abstract}

\title{
Introduction
}

Enhancement of pool boiling heat transfer with the use of functionalized micro/nanostructured surfaces is currently a very popular research area. Surface functionalization of two-phase heat transfer surfaces can be accomplished through a wide range of fabrication techniques ranging from clean room microfabrication to simple etching and deposition techniques [1]. This functionalization of the boiling surface is used to increase micro/nanoscale roughness, capillary wicking, and wettability which lead to increased critical heat fluxes and heat transfer coefficients. Silicon is a very popular base substrate due to the ability to create very controlled surface features. With silicon as a substrate, significant enhancement of the critical heat flux and heat transfer coefficients are accomplished with the fabrication of microposts, nanowires, and nanostructuring [1-7]. These methods resulted in maximum critical heat fluxes around $250 \mathrm{~W} / \mathrm{cm}^{2}[5]$ and maximum feature sizes of around $100 \mu \mathrm{m}$ [3]. Although silicon heat transfer surfaces are very valuable, they aren't always the most practical or real world applications due to the high cost, long manufacturing times, and lack of scalability. 
Metallic surfaces are very popular for industrial applications due to their high thermal conductivities and ease of manufacturing. With the use of highly conductive copper and aluminum surfaces, functionalization is typically achieved with chemical etching processes or deposition techniques which result in maximum feature sizes of only a few microns[8-17], but typically increase the critical heat flux and heat transfer coefficient. Low thermal conductivity and high strength materials like Zircaloy or stainless steel can also be functionalized for performance enhancement. Functionalization of Zircaloy surfaces has been accomplished with the use of an anodization process and was shown to result in critical heat fluxes up to about $200 \mathrm{~W} / \mathrm{cm}^{2}[18,19]$, Surface enhancement techniques for stainless steel and similar metals are limited to coatings and deposition techniques[20-22].

In this paper, a relatively new method for functionalizing metallic surfaces is explored. This method is referred to as femtosecond laser surface processing (FLSP). It uses an ultrafast laser to irradiate the surface and create complex micro/nanostructrures on any metallic surface. This method has previously been used to show the pool boiling enhancement of stainless steel [23]. In this experiment the FLSP technique is being applied to copper pool boiling heat transfer surfaces for the very first time. Varying FLSP microstructures and surface morphologies are studied to fully determine what sort of positive and negative effects FLSP can have on pool boiling performance.

\section{Experimental setup and procedure}

In the present experiment, we functionalized oxygen free copper with FLSP (femtosecond laser surface processing) to create complex selforganized micro/nanostructures. These surfaces were then tested for pool boiling performance to determine the potential this method has on creating a surface capable of dissipating extreme heat fluxes.

FLSP is a technique that uses an ultra-fast femtosecond laser to ablate, melt, and redeposit material to create complex micro/nanostructures on any metallic surface. Microstructures are manufactured with many subsequent laser pulses. Each pulse ablates, melts, and redeposits the base surface material and results in the self-organized microstructures. The microstructure geometry can vary greatly depending on the laser parameters chosen. Two of the controlling laser 
parameters are the laser fluence (power) and shot number. The combination of these two parameters defines the total amount of energy delivered to the surface. Typical microstructure geometries range from densely packed rounded mound structures with heights that range from 10 to 20 microns to higher aspect ratio mounds with heights ranging as high as 100 microns and separated by deep pits. It is important to note that the spot size of the laser is much larger than the self-organized microstructures. In addition, each microstructure also has well developed nanostructure. Typically, taller microstructures are associated with a higher fluence and shot count.

FLSP also has the capability to turn these metal surfaces into highly wetting and wicking surfaces. They produce contact angles of zero and easily produce capillary wicking with high wicking velocities. Also, because of the multiscale nature of the surface, the overall micro and nanoscale surface area is drastically increased.

In this experiment two different classes of surfaces were tested. The first is simply a flat copper surface which was tested as both smooth and processed with three distinct FLSP surface structures. The second class of surface is open copper microchannels that were tested as both unprocessed and processed with varying FLSP structures. These microchannels were manufactured by a precision sawing technique. The microchannels were machined to have a similar width and fin thickness but varying channel depths. The desired depths were .005", .010", and .015" which corresponds to 127,254 , and $381 \mu \mathrm{m}$. The channel width and fin thickness was set to $254 \mu \mathrm{m}$.

Figure 1 presents a schematic of the cross section of the pool boiling experimental set up. The test section is 1.0" in diameter and made from solid oxygen free copper. Five equally spaced thermocouples are embedded in the copper test section to measure the temperature distribution and are used to calculate the heat flux and surface temperature. The power is supplied through five cartridge heaters located in a lower copper heat block and controlled with a variac. This lower heating block is soldered to the test section with a high temperature solder. The test section is insulated with a PEEK bushing and fiberglass insulation (not pictured). The data is then logged with LabVIEW. The system is carefully sealed with a high temperature epoxy to prevent unwanted nucleation at the seam. A more detailed description of the of the pool boiling setup is given by Kruse el al. [23]. 


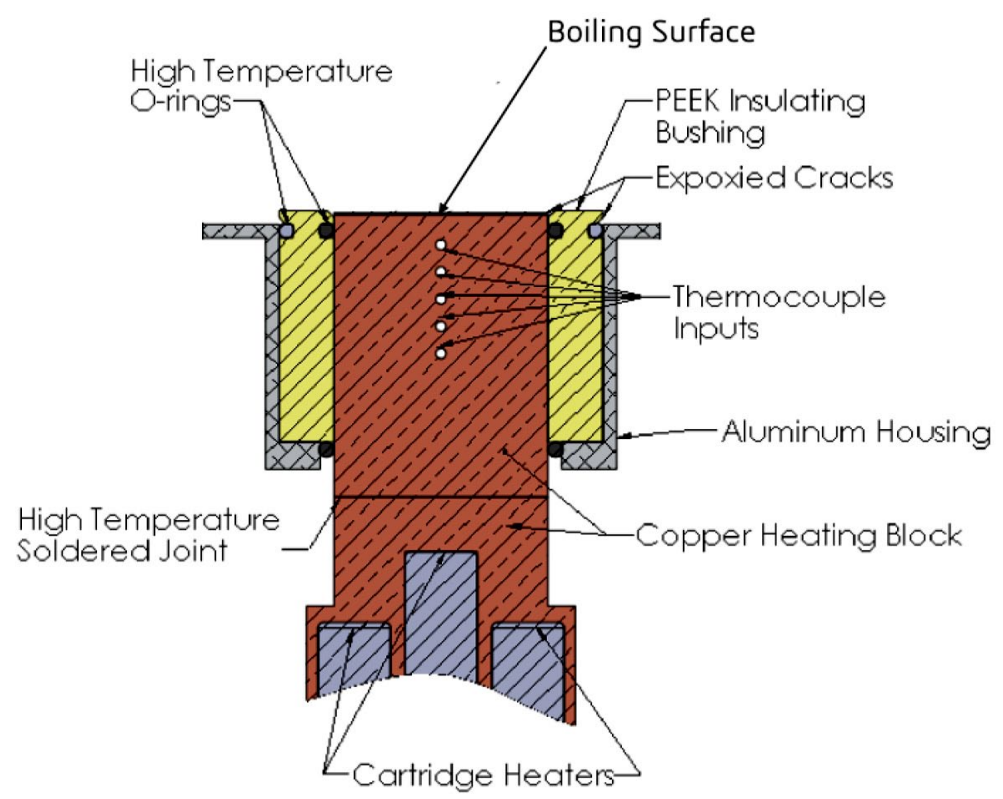

Figure 1. Cross sectional schematic of pool boiling test section

The surfaces were tested for pool boiling performance with deionized water as the working fluid. The complete system holds about eight liters of water. The water was brought the saturation temperature with an immersion heater and allowed boil for about an hour in order to degas the liquid. The power to the test section was incrementally increased and once a steady state was reached the heat flux and surface temperature were recorded. The liquid temperature and chamber pressure were also monitored.

\section{Results and disscusion}

In total, six FLSP surfaces were created. These can be seen in Figure 2. Those corresponding to the flat surface series are labeled S1-S3 and the microchannel surfaces are MC1-MC3. With respect to the flat surfaces, S1 to S3 has a trend of decreasing laser fluence with $\mathrm{S} 1$ having the highest, $40.2 \mathrm{~J} / \mathrm{cm}^{2}$ and S2 and S3 having a fluence of 9.3 and 5.6, respectively. As seen in Figure 2, there appear to be more deep pits surrounding the mound structures in $\mathrm{S} 1$, which gives a larger peakto-valley height. As the fluence decreases, the mounds become more 


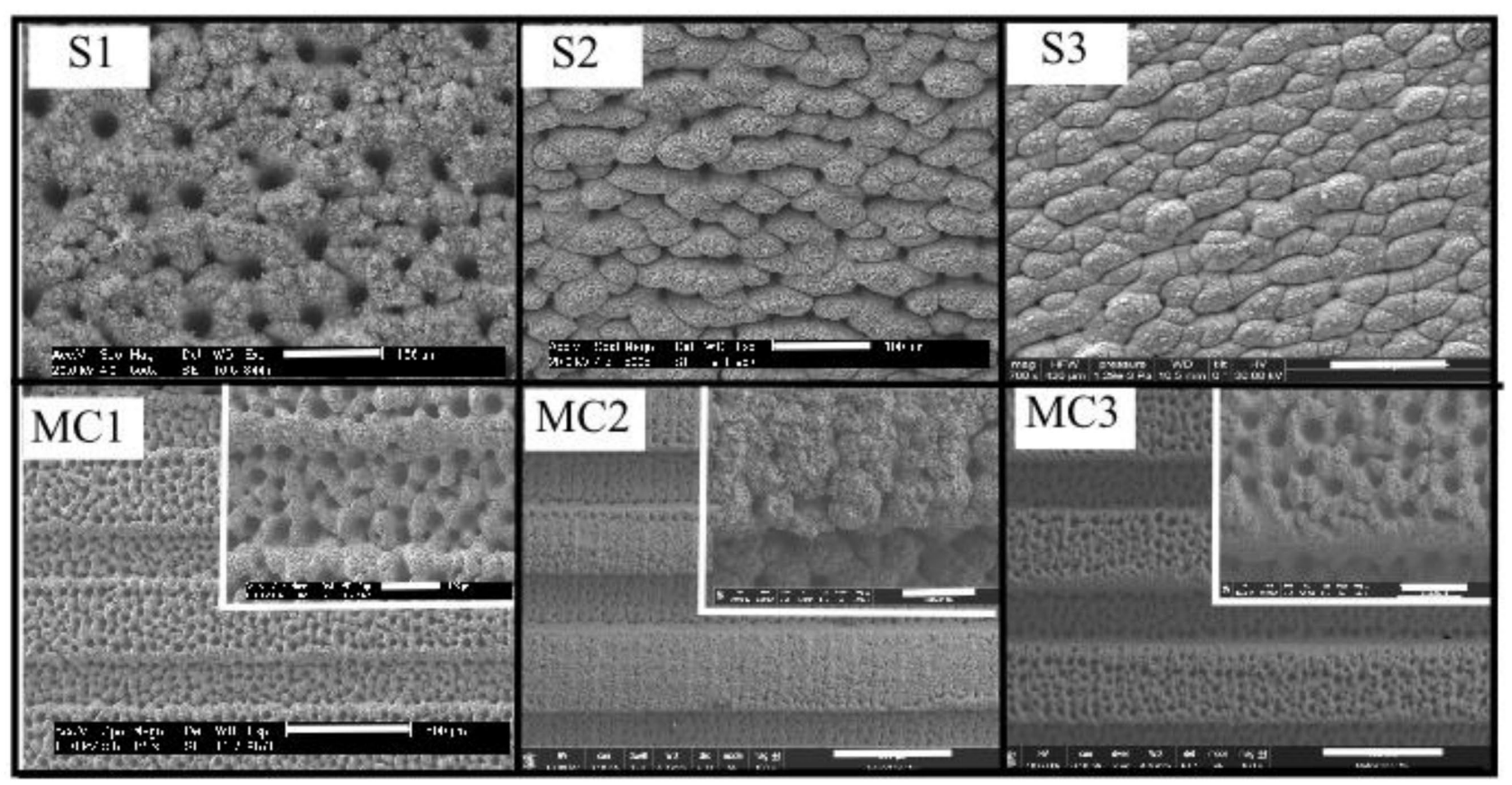

Figure 2. SEM images of each FLSP surface. Top: Flat series, scale bars of $100 \mu \mathrm{m}$. Bottom: Microchannel series, scale bars of $500 \mu \mathrm{m}$ and $100 \mu \mathrm{m}$ for the inserts

rounded, shorter, and denser. The deep pits surrounding the mounds are replaced with "cracks" which separate each mound. The microstructure mound peak-to-valley heights range from about 25 (S3) $\mu \mathrm{m}$ to $60 \mu \mathrm{m}(\mathrm{S} 1)$.

With respect to the microchannel series, MC1 corresponds to the $125 \mu \mathrm{m}$ and MC2 and MC3 correspond to the 254, and $381 \mu \mathrm{m}$ channel heights, respectively. MC1 and MC3 were both processed with the same laser fluence and shot combination to create similar microstructures. MC1 and MC3 were both created with a higher fluence than MC2 and as expected the microstructures displayed more pit formations. Unfortunately, the laser fluence parameters were not recorded during the processing of these specific structures.

The flat surface series was tested first. A polished copper reference sample was fabricated and then tested for pool boiling heat transfer performance. This sample was polished to a mirror finish by a series of buffing wheels and compounds. It is important to note that although the surface was smooth for testing, it was oxidized before testing. Due to the high temperature solder used to join the test section to 


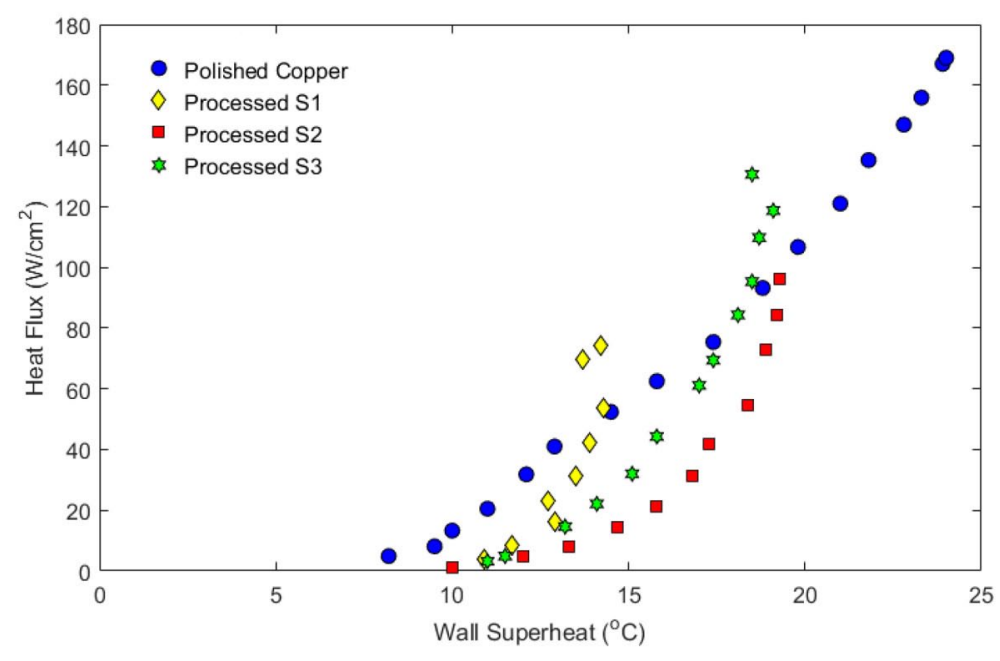

Figure 3. Boiling curve for the flat series with and without FLSP

the heating block, the test section was exposed to $300{ }^{\circ} \mathrm{C}$ temperatures for around 10 minutes to make the connection. This changed the appearance of the copper surface from a bright shiny luster to a duller darker appearance.

All processed samples were created one at a time and then tested in order to minimize exposure and potential contamination. The S1 sample was created first. The chosen type of microstructure was based on our previous results with stainless steel materials [23][25]. With respect to these tests, the tallest structures typically produced the largest critical heat fluxes and heat transfer coefficients. The data corresponding to the flat surface series can be seen in Figure 3. The results corresponding to $\mathrm{S} 1$ were quite surprising. We saw a dramatic decrease in the critical heat flux and heat transfer coefficient in comparison to the polished reference curve. S1 resulted in a CHF of about 75 $\mathrm{W} / \mathrm{cm}^{2}$ in comparison to a $\mathrm{CHF}$ of $167 \mathrm{~W} / \mathrm{cm}^{2}$ for the polished sample. The shift of the curve to the right for $\mathrm{S} 1$, indicated a reduction in HTC. This dramatic reduction in CHF and HTC was never seen before on any previous FLSP surfaces. This was not expected at all due to the nature of FLSP surfaces. This technique impacts several areas that are well known to influence CHF and HTC in a positive way. These FLSP surfaces are highly wetting with contact angles of zero and produce substantial capillary wicking. In addition, the overall surface area is significantly increased due to the micro/nanostructures. This substantial 
change in the boiling performance led to further exploration of FLSP copper surfaces.

Sample S2 was fabricated with a lower laser fluence than S1, this created shorter mound structures with less obvious pits between the structures. This surface was also tested in the exact same manner as S1. It was found that the CHF was higher, about $96 \mathrm{~W} / \mathrm{cm}^{2}$, but was still significantly lower than the reference sample. The curve also shifted further to the right indicating a reduction in the heat transfer coefficient. An additional microstructure surface (S3) was fabricated with an even lower fluence and thus created shorter and denser microstructures. Once again the $\mathrm{CHF}$ was even higher, about $130 \mathrm{~W} / \mathrm{cm}^{2}$, but the HTC was still lower throughout most of the boiling curve.

From this data, it is evident that there is something very significant controlling the heat transfer performance of these FLSP surfaces, especially since we have previously seen significant enhancement for other metallic boiling surfaces. In the low heat flux regions of the boiling curves, the heat transfer coefficients are all significantly lower than the polished surface even though there is a substantial increase in surface area which is typically associated with an increase in HTCs. In the higher heat flux regions, the curve also begins to change slope indicating that the heat transfer coefficient is increasing.

To further understand the controlling mechanism with these copper FLSP surfaces, an additional surface geometry was introduced. Open microchannels were machined into the surface with varying depths. For each depth, both an FLSP and unprocessed surface was tested. These microchannels are significantly larger than the FLSP microstructures. The goal was to see if the addition of FLSP with varying fluence (varying microstructures) would overcome the additional enhancement introduced by the microchannels themselves. Instead of varying all three fluence values, only two were chosen for this series. These two fluence values correspond to tall microstructures with very significant pit formation and shorter microstructures with virtually no pit formations. Although the specific fluence values were not recorded for this series, from the type of microstructure formation, it is expected that the high fluence sample is greater than S1 and the low fluence sample is less than S3. The pool boiling data corresponding to these surfaces can be seen in Figure 4 .

As expected, the addition of the open microchannels increased the heat transfer coefficient compared to the corresponding unprocessed 


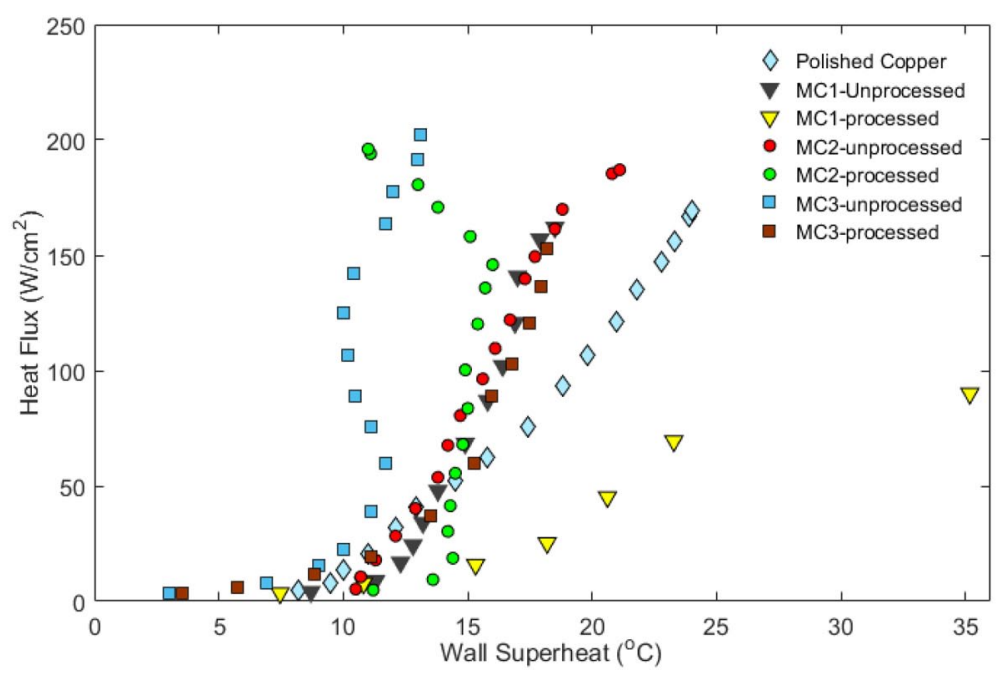

Figure 4. Boiling curve for the microchannel surfaces with and without FLSP

test surfaces. The tallest channel surface produced the largest change in HTC while the other two samples saw a slight increase compared to the polished reference sample. The critical heat flux was significantly enhanced for the tallest microchannel surface (MC3), up to about 202 $\mathrm{W} / \mathrm{cm}^{2}$. The shortest microchannel surface saw no real change in $\mathrm{CHF}$ with a measured value of $162 \mathrm{~W} / \mathrm{cm}^{2}$ while for the medium channel height (MC2) a CHF of $187 \mathrm{~W} / \mathrm{cm}^{2}$ was measured.

The shortest and tallest microchannel surfaces were both processed with the high laser fluence, giving the deep pit characterization and the tallest microstructures. Once again these surfaces were all highly wetting and wicking before testing. For these microchannel surfaces, the unprocessed surface was first tested for pool boiling performance and then that exact same surface was laser processed and then tested in order to rule out any inconsistencies from attempting to manufacture two identical microchannel surfaces. With the high fluence surfaces (MC1 and MC3), after processing, both surfaces saw very drastic decreases in heat transfer performance. For MC1 the CHF dropped from $162 \mathrm{~W} / \mathrm{cm}^{2}$ to $90 \mathrm{~W} / \mathrm{cm}^{2}$ while for MC3 the CHF dropped from $202 \mathrm{~W} / \mathrm{cm}^{2}$ to $152 \mathrm{~W} / \mathrm{cm}^{2}$. This also resulted in a change in HTC for $\mathrm{MC} 1$ from $87,600 \mathrm{~W} / \mathrm{m}^{2}-\mathrm{K}$ to $25,700 \mathrm{~W} / \mathrm{m}^{2}-\mathrm{K}$ and change from 154,200 $\mathrm{W} / \mathrm{m}^{2}-\mathrm{K}$ to $84,400 \mathrm{~W} / \mathrm{m}^{2}-\mathrm{K}$ for MC3 at the CHF location.

The results for the MC2 surface were vastly different. This surface was processed with a very low laser fluence and displayed relatively 
small microstructures. This was the only FLSP copper surface that produced positive heat transfer results compared to its corresponding unprocessed surface. The MC2 processed surface resulted in an increase in the $\mathrm{CHF}$ from $187 \mathrm{~W} / \mathrm{cm}^{2}$ to $194 \mathrm{~W} / \mathrm{cm}^{2}$. With this surface, we also observed a hook back in the boiling curve, which we refer to as secondary boiling effects. This phenomenon is usually displayed with appropriate FLSP pool boiling surfaces; detailed description of this phenomenon is given by Kruse et al.[25].

It is also very important to note, that with this sample, we did not observe the general decrease in HTC as can be seen with the other two processed copper surfaces. In fact, we observed an increase in the HTC. The maximum HTC increased from $88,600 \mathrm{~W} / \mathrm{m}^{2}-\mathrm{K}$ to $174,800 \mathrm{~W} /$ $\mathrm{m}^{2}-\mathrm{K}$. It is clear that the laser fluence plays a major role in the overall heat transfer performance. Common trends found in the literature though, are not followed. Typically, when wettability is increased, capillary wicking is introduced, and the surface area is increased the critical heat flux and heat transfer coefficients increase. It is suspected that the answer lies in the characteristics of the material layer modified through FLSP.

To determine what was beneath the surface, a new method was employed to characterize the modified layers. Focused lon Beam milling was used to cross section individual microstructures to see the internal makeup of them. Prior to milling, approximately $100 \mathrm{~nm}$ of carbon was deposited and followed by a much thicker layer of platinum. This is used as a protective layer to preserve the outer layer of the microstructure. Then an ion beam is focused at an angle and is used to slowly mill away the material from the side. This process is continued till the exposed area is about midway through a mound structure. Then, a polishing technique is applied which smooths out the exposed material allowing for the visualization of the different layers and grain structure. This process was conducted on all of the microchannel FLSP surfaces. Figure 5 only shows MC3 and MC2. MC1 was similarly cross sectioned but due to the identical laser parameters used, the results did not vary from MC3.

It can be seen from the cross section images that there are clearly different layers within the microstructure. It is also evident that the overall geometry varies greatly between the two samples. To fully determine the chemical makeup of each layer an EDS line scan was 

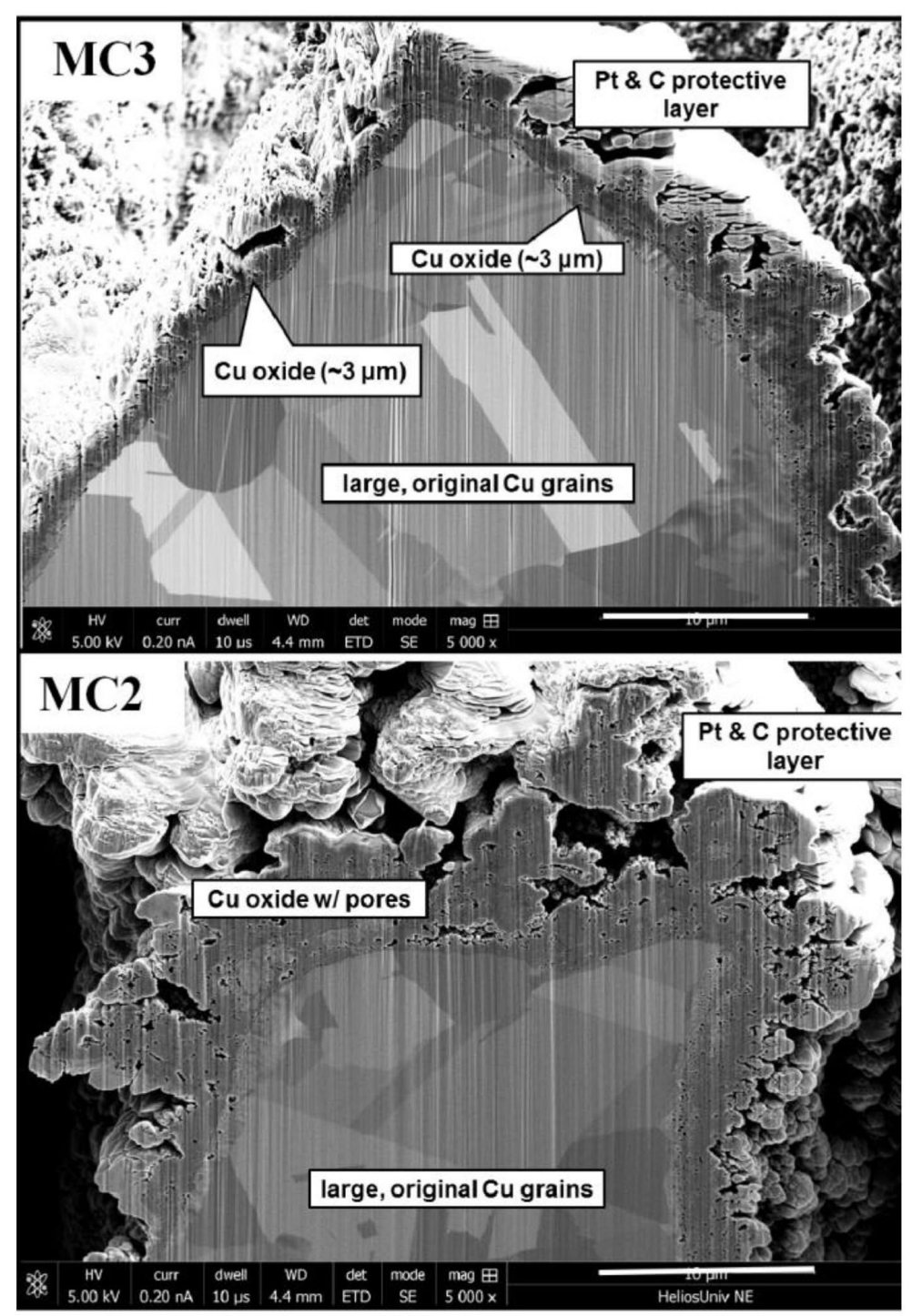

Figure 5. Cross section SEM images of MC3 and MC2 FLSP Structures

completed. This gives the elemental makeup at a specific location along a desired path. This data is shown in Figure 6. From this data, it was found that there is a significant oxide layer on top of the core copper material. There is also a very fine layer of fine grain copper between the large original grains and the oxide layer. This oxide layer is also very porous and filled with voids.

The findings from the cross sectioning can help to explain the heat transfer results. The key component is the oxide layer. This oxide layer grows due to the large amount of energy transferred to the surface 

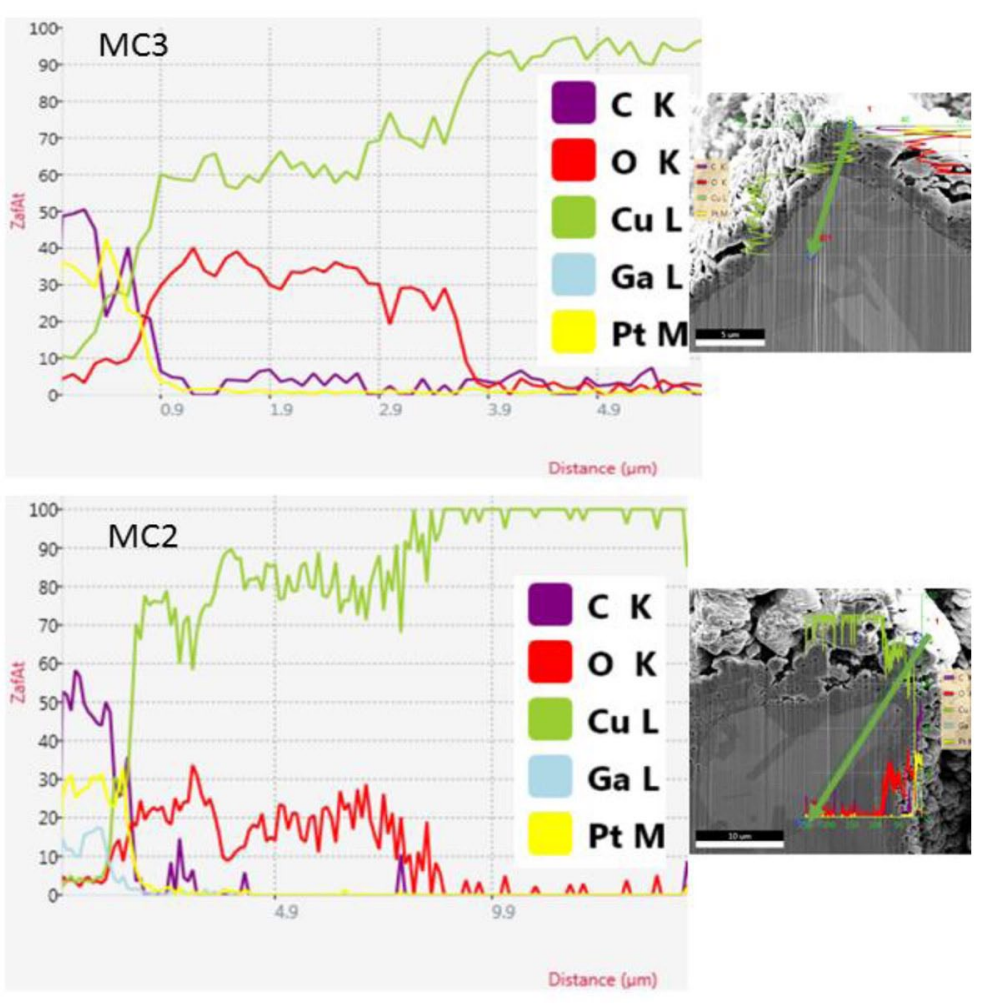

Figure 6. EDS line scan data for MC3 and MC2. This data shows the transition between different layers: the protective carbon and platinum layer, the oxide layer, and the bulk material.

during FLSP. This energy induces surface melting and fluid flow followed by rapid quenching. This process is also performed under atmospheric conditions which allows for the molten metal to oxidize. With respect to the fluence parameter, the higher the fluence the more melting that takes place. With higher fluence also comes more uniform melting which results in a more uniform oxide layer. This is seen by MC3 compared to MC2. MC3 has a nearly uniform oxide layer of around 3 to 4 microns thick across the entire microstructure. In the case of MC2 this layer is much more uneven with areas of very thick oxide layers and areas of very little.

This oxide layer thickness and geometry explains the vast difference in heat transfer results between the two samples. MC3 resulted in a significant drop in CHF and HTC. This is because the oxide layer acts as an insulator due to the lower thermal conductivity and since there are air voids inside the layer. This additional thermal resistance 
across the interface increases the bulk material temperatures and lowers the HTC. The lateral heat spreading ability will also be relatively low which can allow for local hot spots to grow and a stable vapor film to develop that leads to the critical heat flux. In the case of the MC2 surface, this oxide layer is very uneven. This allows for areas with low thermal resistance, as well as high thermal resistance.

In the areas of thin oxide layer and low thermal resistance, efficient heat transfer can occur with the liquid. It is also worth noting that MC2 has many reentrant cavities, which are well known to be ideal for nucleation. In all pool boiling surfaces there are competing factors that govern the overall performance. Wettability, capillary wicking, enhanced surface area, and abundant nucleation cavities all contribute to the overall heat transfer capability while the surface thermal resistance and heat spreading capacity can negatively affect performance. In the case of these FLSP surfaces it is evident that there is a significant resistance at the surface due to the oxide layer. This oxide layer increases surface temperatures and allows local hot spots to grow faster than heat conduction and liquid spreading can cool them, resulting in a premature $\mathrm{CHF}$.

The next step in studying FLSP copper surfaces for pool boiling performance is to determine a way to optimize this oxide layer or completely eliminate it. With the control of the oxide layer, these FLSP surfaces can take full advantage of the positive attributes like the highly wetting and wicking nature and increased heat transfer area and nucleation cavities.

\section{Conclusion}

In this study two series of multiscale functionalized surfaces were created with the use of a femtosecond laser surface processing (FLSP) technique. This technique creates complex self-organized micro/nanostructures on any metallic surface. A series of FLSP surfaces were created on flat and microchannel substrates. Three unique flat and three microchannel FLSP surfaces were created and tested for pool boiling performance. As indicated from previous work with stainless steel FLSP pool boiling surfaces, an increase in critical heat flux and heat transfer coefficient was expected. This was not the general trend seen 
with these copper FLSP surfaces. All of the FLSP surfaces, except one, resulted in a decrease of the CHF and HTC. A new focused ion beam milling technique was used to cross section individual microstructures in order to determine the underlying cause of the drop in performance. It was found that a substantial oxide layer is present on the top of the microstructure mounds. This oxide layer increases the thermal resistance of the system and promotes hot spot growth which offsets the performance gains due to capillary wicking and increased surface area and results in early CHF and lower HTCs. The surface that displayed positive heat transfer results displayed a very uneven oxide layer that also had many reentrant cavities which promote efficient nucleation.

Acknowledgments This work has been supported by a grant through the $\mathrm{Ne}$ braska Center for Energy Sciences Research (NCESR) Grant \# 803, A- 00-A-03, a NASA EPSCoR Grant \# 2014-198-SC1, a NASA Space Technology Research Fellowship (NSTRF) Grant \# NNX14AM50H, and an Office of Naval Research (ONR) Grant \# FA4600-12-D-9000-0045.

\section{References}

[1] M.-C. Lu, R. Chen, V. Srinivasan, V.P. Carey, A. Majumdar, Critical heat flux of pool boiling on Si nanowire array-coated surfaces, Int. J. Heat Mass Transf. 54 (2011) 5359-5367. doi:10.1016/j.ijheatmasstransfer.2011.08.007.

[2] Z. Yao, Y.-W. Lu, S.G. Kandlikar, Effects of nanowire height on pool boiling performance of water on silicon chips, Int. J. Therm. Sci. 50 (2011) 2084-2090. doi:10.1016/j.jijthermalsci.2011.06.009.

[3] Z. Yao, Y.-W. Lu, S.G. Kandlikar, Micro/nano hierarchical structure in microchannel heat sink for boiling enhancement, in: 2012 IEEE 25th Int. Conf. Micro Electro Mech. Syst., IEEE, 2012: pp. 285-288. doi:10.1109/ MEMSYS.2012.6170150.

[4] M. Rahman, S.M. King, E. Olceroglu, M. Mccarthy, Nucleate Boiling on Biotemplated Nanostructured Surfaces, in: ASME 2012 Int. Mech. Eng. Congr. Expo. Am. Soc. Mech. Eng., 2012: pp. 2801-2808.

[5] R. Chen, M.-C. Lu, V. Srinivasan, Z. Wang, H.H. Cho, A. Majumdar, Nanowires for enhanced boiling heat transfer., Nano Lett. 9 (2009) 548-53. doi:10.1021/ nl8026857.

[6] A.R. Betz, J. Jenkins, C.-J. "Cj" Kim, D. Attinger, Boiling heat transfer on superhydrophilic, superhydrophobic, and superbiphilic surfaces, Int. J. Heat Mass Transf. 57 (2013) 733-741. doi:10.1016/j.jheatmasstransfer.2012.10.080. 
[7] K.-H. Chu, R. Enright, E.N. Wang, Structured surfaces for enhanced pool boiling heat transfer, Appl. Phys. Lett. 100 (2012) 241603. doi:10.1063/1.4724190.

[8] S. Das, S. Bhaumik, Enhancement of Nucleate Pool Boiling Heat Transfer on Titanium Oxide Thin Film Surface, Arab. J. Sci. Eng. 39 (2014) 7385-7395. doi:10.1007/s13369-014-1340-z.

[9] B. Feng, K. Weaver, G.P. Peterson, Enhancement of critical heat flux in pool boiling using atomic layer deposition of alumina, Appl. Phys. Lett. 100 (2012) 053120. doi:10.1063/1.3681943.

[10] E. Forrest, E. Williamson, J. Buongiorno, L.-W. Hu, M. Rubner, R. Cohen, Augmentation of nucleate boiling heat transfer and critical heat flux using nanoparticle thin-film coatings, Int. J. Heat Mass Transf. 53 (2010) 58-67. doi:10.1016/j.ijheatmasstransfer.2009.10.008.

[11] T.J. Hendricks, S. Krishnan, C. Choi, C.-H. Chang, B. Paul, Enhancement of pool-boiling heat transfer using nanostructured surfaces on aluminum and copper, Int. J. Heat Mass Transf. 53 (2010) 3357-3365. doi:10.1016/j. ijheatmasstransfer.2010.02.025.

[12] Y. Im, C. Dietz, S.S. Lee, Y. Joshi, Flower-Like CuO Nanostructures for Enhanced Boiling, Nanoscale Microscale Thermophys. Eng. 16 (2012) 145-153. doi:10.1 080/15567265.2012.678564.

[13] C. Li, Z. Wang, P.-I. Wang, Y. Peles, N. Koratkar, G.P. Peterson, Nanostructured copper interfaces for enhanced boiling., Small. 4 (2008) 1084-8. doi:10.1002/ smll.200700991.

[14] J.P. McHale, S. V. Garimella, T.S. Fisher, G. a. Powell, Pool Boiling Performance Comparison of Smooth and Sintered Copper Surfaces with and Without Carbon Nanotubes, Nanoscale Microscale Thermophys. Eng. 15 (2011) 133150. doi:10.1080/15567265.2011.575918.

[15] D. Saeidi, a. a. Alemrajabi, Experimental investigation of pool boiling heat transfer and critical heat flux of nanostructured surfaces, Int. J. Heat Mass Transf. 60 (2013) 440-449. doi:10.1016/j.ijheatmasstransfer.2013.01.016.

[16] Y. Tang, B. Tang, Q. Li, J. Qing, L. Lu, K. Chen, Poolboiling enhancement by novel metallic nanoporous surface, Exp. Therm. Fluid Sci. 44 (2013) 194-198. doi:10.1016/j.expthermflusci.2012.06.008.

[17] P. Xu, Q. Li, Y. Xuan, Enhanced boiling heat transfer on composite porous surface, Int. J. Heat Mass Transf. 80 (2015) 107-114. doi:10.1016/j. ijheatmasstransfer.2014.08.048.

[18] H.S. Ahn, C. Lee, H. Kim, H. Jo, S. Kang, J. Kim, J. Shin, M.H. Kim, Pool boiling CHF enhancement by micro/nanoscale modification of zircaloy-4 surface, Nucl. Eng. Des. 240 (2010) 3350-3360. doi:10.1016/j.nucengdes.2010.07.006.

[19] H.S. Ahn, C. Lee, J. Kim, M.H. Kim, The effect of capillary wicking action of micro/nano structures on pool boiling critical heat flux, Int. J. Heat Mass Transf. 55 (2012) 89-92. doi:10.1016/j.ijheatmasstransfer.2011.08.044.

[20] J. Cieśliński, Nucleate pool boiling on porous metallic coatings, Exp. Therm. Fluid Sci. 25 (2002) 557-564. http://www.sciencedirect.com/science/article/ pii/S0894177701001054 (accessed December 11, 2014). 
[21] H.T. Phan, N. Caney, P. Marty, S. Colasson, J. Gavillet, Surface wettability control by nanocoating: The effects on pool boiling heat transfer and nucleation mechanism, Int. J. Heat Mass Transf. 52 (2009) 5459-5471. doi:10.1016/j.ijheatmasstransfer.2009.06.032.

[22] G.H. Seo, H. Hwang, J. Yoon, T. Yeo, H.H. Son, U. Jeong, G. Jeun, W. Choi, S.J. Kim, Enhanced critical heat flux with single-walled carbon nanotubes bonded on metal surfaces, Exp. Therm. Fluid Sci. 60 (2015) 138-147. doi:10.1016/j. expthermflusci.2014.08.015.

[23] C.M. Kruse, T. Anderson, C. Wilson, C. Zuhlke, D. Alexander, G. Gogos, S. Ndao, Enhanced pool-boiling heat transfer and critical heat flux on femtosecond laser processed stainless steel surfaces, Int. J. Heat Mass Transf. 82 (2015) 109-116. doi:10.1016/j.ijheatmasstransfer.2014.11.023.

[24] C.M. Patil, S.G. Kandlikar, Pool boiling enhancement through microporous coatings selectively electrodeposited on fin tops of open microchannels, Int. J. Heat Mass Transf. 79 (2014) 816-828. doi:10.1016/j. ijheatmasstransfer.2014.08.063.

[25] C. Kruse, A. Tsubaki, C. Zuhlke, T. Anderson, D. Alexander, G. Gogos, S. Ndao, Secondary pool boiling effects, Appl. Phys. Lett. 108 (2016). doi:10.1063/1.4941081. 